\title{
Impact of Information System on Transformation of Human Resource Performance: An Exploratory Study in Oromia Radio and Television Organization
}

\author{
Tanjim Tomanna1, Dawit Yadeta Gerbi², Md. Altab Hossin³ ${ }^{3}$ Shiyun Zhang1 \\ ${ }^{1}$ School of Economics \& Management, Chongqing University of Posts and Telecommunication, Chongqing, China \\ ${ }^{2}$ Oromia Broadcasting Network, Adama, Ethiopia \\ ${ }^{3}$ School of Management and Economics, University of Electronic Science and Technology of China, Chengdu, China \\ Email: tanjim.mz@qq.com
}

How to cite this paper: Tomanna, T., Gerbi, D.Y., Hossin, M.A. and Zhang, S.Y. (2018) Impact of Information System on Transformation of Human Resource Performance: An Exploratory Study in Oromia Radio and Television Organization. Journal of Human Resource and Sustainability Studies, 6, 37-52.

https://doi.org/10.4236/jhrss.2018.61025

Received: December 23, 2017

Accepted: March 19, 2018

Published: March 22, 2018

Copyright $\odot 2018$ by authors and Scientific Research Publishing Inc. This work is licensed under the Creative Commons Attribution International License (CC BY 4.0).

http://creativecommons.org/licenses/by/4.0/

\section{(c) (i) Open Access}

\begin{abstract}
In the last few decades, emerging hyper-competitive era has increased the demand of information system and technology on human resource management for competitiveness. The revolution of information system and technology is completely and rapidly redefining the way of things are done in almost every field of human activity. Many firms are looking for utilizing the two elements (human resources and information system) as strategic weapons to compete. In particular, information system is demonstrated for human resource management that referred as human resource information system (HRIS). The HRIS is an integrated system mostly used to collect data, govern, record and to deliver and present data for human resource and hence promotes and transforms appropriateness of transforming human resource performance. This paper focuses on the impact of information system on transformation of human resource performance, the case of Oromia radio and television organization in Ethiopia. Both literature studies and interviews were done in this study to accrue information.
\end{abstract}

\section{Keywords}

Human Resource Information System, Transformation, Information Technology, Human Resource

\section{Introduction}

The human resource industry has revolutionized the contemporary workplace 
with the addition of information technology. Human resource professionals, recently, have increased capacity in order to gather information. In addition, they are also highly capable to store and retrieve it in a timely and efficacious manner. The HR transformation is a process of reconstructing the HR function to the adeptness and the motive of the organization. To catch the desire success, HR can become a true partner of any type of organization. The intent of HR transformation is not simply to improve the efficiency of processes but to improve the function's effectiveness. It addresses entire elements of HR including its structure and demonstration, employee deployment, use of technology, processes designing, service delivery and so on. As this HR transformation helps to increase the efficiency of the organization and also, respectively, boosts up the effectiveness of management functions. In every HR department, HRIS has an effective streamline administrative function to reach the goal of HR performance transformation. In a consequence, the HRIS is now deliberated an integral part of every organization [1]. An effective HRIS data that would have on particular office personnel can include training accomplished, rewards received, projects participated and completed successfully, level of education acquired, work proficiency, competencies, etc. The HR department can make a contribution by analysing these data onto strategy formation of an organization.

Recently, some significant changes have been noticed that, HR professionals now concentrate more on business strategic issue with the top managers instead of interacting with employee management [2] [3]. This extensive movement towards the HR function can strongly be illustrated as simple as "changing", but "transformation" instead. It employs reinvention, reposition, and renovation of the HR functions' activity and obligation [4]. The personnel of HR takes part in various transformative projects to accomplish the transformation [4]. For example, reforming the work methods and HRM system, reconstructing service delivery process, and managing cultural change can play a vital role in this circumstance. To be compatible with such challenging activities, the HR personnel may elevate their management proficiency to enhance the transformation by useful techniques [5] that might improve leadership and exceed any obstacles to make sure right direction [6]. After ensuring these parameters, the transformative activities can earn positive effect and enhance the performance of the organization. HR professionals are better able to handle large amounts of information efficiently by deploying information technology that might bring efficiencies to the administrative HR.

However, no researchers have been done earlier in Oromia radio and television organization in Ethiopia on the area of impact of information system/IT on transformation of human resource performance, therefore, there is still a gap. In this regard, we contribute to understanding the impact of information system/IT on transformation of human resource performance, particularly in Oromia radio and TV Organization. Information system/IT has also enhanced government work via reliable infrastructure, skilled human resources, open government and 
other essential issues of capacity building and also developing centres to improve IT capabilities especially at top, middle and low level management.

This research is concerned with the impact of information system/IT on transformation of human resource performance, the case of Oromia radio and television organization: Oromia Radio and TV organization are one of the state media among all media which were found in Ethiopia. It has been established under the Proclamation No. 113/2006 of the Oromia regional council in Oromia region Adama town, making Oromia radio and television organization an independent legal entity of broadcast section. The organization is accountable to the council of Oromia national regional state, with its head quarter Finfinne (Addis Ababa), the nation capital.

\section{Transformation of the HR Function}

The trade world is turning to high demand by cumulative competition and globalization in the world business, the claiming of rising competency for long term development, and the advancement of productivity to gain market share. These kind of demands have compelled organizations to reconsider how they can keep or attain their competitive advantage in the continuous transforming market environment through utilizing the best use of their man power [7]. In addition, there are other parameters are tending organizations to revise their HR function to fill up the demands of the strategic business and the consequence corporate success, such as changing business environment, customer gratification, diversity of management, and prosperity of knowledge and technology [4] [8]. These driving capacities influence the HR function to amplify under the pressure on environment and to eliminate the downside of existing systems.

People always play vital role in order to bring success of business. In the progression of international trade, the workforce can be classified based on universal variables as gender, socio-economic status, geography, and generation gaps [9]. For instance, the raising number of aging people in the developed countries and changing values of the new generation of the under-developing countries must require elementary change of the tasks of the personnel management [10]. The diverse value and multi-cultural working environment can be ensured by the multi classifications of worker where the HR professionals must have to take steps to build up harmonious atmosphere in organization and broadly admissible work values.

The improvement to technology is the last driven force for HR transformation function. In order to enhance the business competence requires technology through various aspects. For instance, technology might help to modify the management of information and also reduce the burden of handling and revealing information of human resource department. The advancement and rapid changes of technology also lead the HR personnel to update with new skills through education, or hiring expert HR professionals' who has certain IT ability in those fields. A survey (interview) was conducted by Yeung et al. (1994) [11], 
reveals that a significant number of companies (more than half of the companies) who use the HRIT systems that is integrated their database and their information system provide much better information and easier access to analyse the collected data to their managers and personnel. In consequence, another informatics research was conducted by Sagie and Weisberg (2001) [9] on HR function in different companies in Israel. The report reveals that the HR department has been divided into two parts on basis of technology levels: the high-tech and low-tech sectors. The high-tech sector concentrates on the strategic issues and low-tech focus on consecutive tasks. The operation of HR requires to synthesise itself in order to increase the advantage of using HRIT.

Depending on the meaning of changes, Appelbaum and Wohl (2000) [4] describe the word transformation. They come to the point that both change and transformation are committing something different from prior circumstance. Changing payoff progresses in specific areas when such exchange is necessary. The aim of changing should already exist and the result of change is to make things different or even improved. In constraint, transformation concentrates on discovering new things that completely new instead of improving as they noted that gradual transformation define as "reinvention". So it could be mentioned that transformation forces for discovering new context to make thing work better. According to Stockport (2000) [7], the transformation is also a kind of variation but more fundamental, and more likely to occur internally, concerning an organization. This kind of transformation may appear in the systems, structures, employees or culture. According to the etymology, a transformation in HR function can be explained into two aspects: in the first place, the main tasks of HR experts have altered. A tardy and gradual change in HR department, by changing its construction, or out-sourcing the entire HR department [6] [12], happens to meet the need of the organization [10] [13]. The basic administration, the centre of the HR work is no longer, though it tends toward the management expert to the consulate and tactics aspects. In the second place, it is an alternative to administration level. An excellent evident change is typically the engaging of line office manager and employees into the staffing issue along together with the human resource experts.

To conclude, transformation is a kind of business processes that alters the duties and broads the participations of actors in HR function, and that commits HRM focusing more on tactical, value-creating activities for the long-term stability.

\section{Human Resource Information System (HRIS)}

Nowadays, HRIS is deployed Human Resource Management and Information Technology in one frame. Latest progressions of technology are collaborating to establish real-time information-based, self-service, and interactive work environment. Personnel information systems have developed from the robotic employee record keeping from the 1960s into more elaborate reporting and deci- 
sion systems of late [14]. Today, managers and employees are pretending activities once deliberated the ambit of human resource professionals and administrative personnel. This not only represents a substantial disruption with the past, but also an enhancement of overall organizational effectiveness. Therefore, given the authority and relevant accessible information for decision-making, both managers and employees respond more quickly to changes [15] [16]. Kovach et al., (1999) presented the three major functional components in any HRIS by giving the model in Figure 1. The Input functions receive the personnel information into the HRIS. In the past, data entry was only the one way, but now a day, scanning technology permits scanning and storage of actual image off an original document, which includes signatures and handwritten notes together. The maintenance functions work to improve and provide new data to the database after data have been moved into the information system.

In particular, the most noticeable function of HRIS, is the output production. According to Kovach et al., (1999) [16], to produce valuable output for computer users, the HRIS need to process all output by making the necessary calculations, and formatting the particular presentation in a method that might be understood. Additionally, for individuals who have already used HRIS, most of them can't realize its complete benefits. In his one survey Towers Perrin identified that just 3\% was speeding up HR's transformation to the strategic partner and just $5 \%$ fully accomplished this objective; one more $35 \%$ had simply partially achieved that aim, even though $80 \%$ associated with participants affirmed employee self-services ability to lower FIR costs (Ibid). HRIS allows in recording in addition to examining employees and company information and documents, for example employee hand books, unexpected emergency evacuation and safety processes [17]. Additionally, it assists the companies to keep an appropriate, complete and update data base that can be reclaimed through reports and instructions.

\section{Human Resource Information System on HR Function Transformation}

HRIS feature is a combination of human resource management (HRM) and Information Technology. However, HRIS systems may depend on integrated hardware resources operationally, a group of tech experts lying within the personnel department increasingly manage, support, and maintain them. HRIS assist for planning, administration, decision-making, and controlling the HR activities.

The HRIS system can be used for various purposes including employee enrolment and allocation, payroll, retirement fund, and benefits management, intake and training projections, career-pathing, equity monitoring, productivity evaluation and so on. Figure 2 shows the overall benefits of Human resource information system [18].

To increase administrative efficiency and produce reports capable of improving decision-making uses these information systems [14]. Since 1990s, HR has 


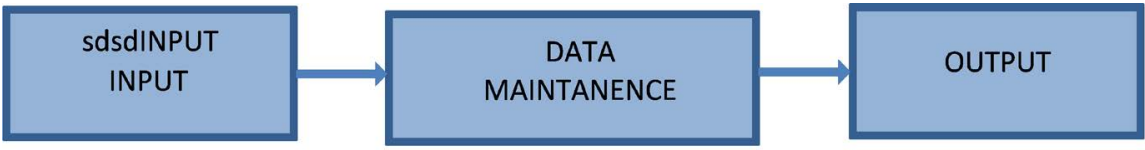

Figure 1. Components of human resource information systems.

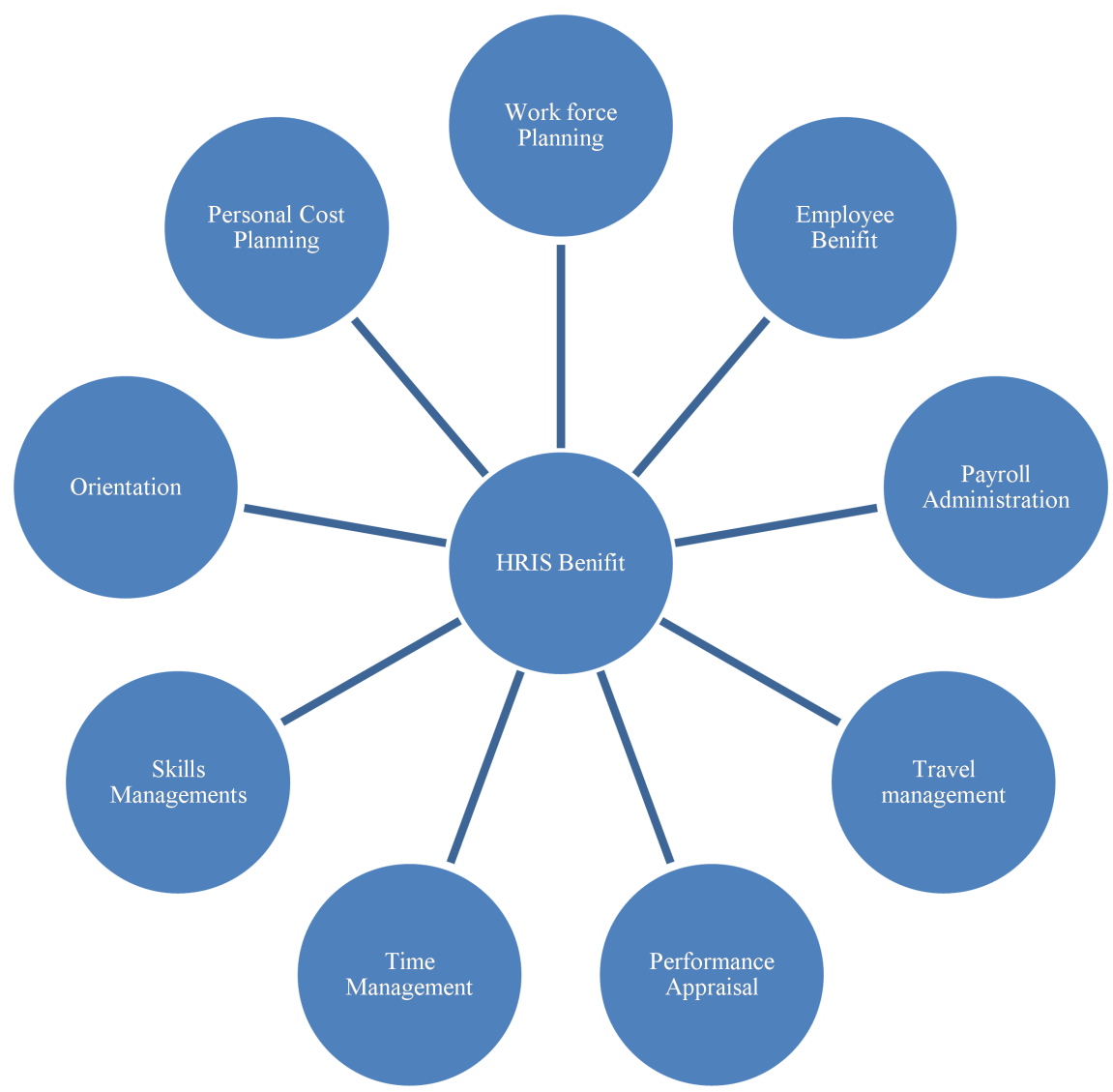

Figure 2. Overall benefits of Human resource information system.

been evolved in the application of Human resource information system, the effects of information and technology on HRM are increasing over the last few years [19]. In order to justify its power of conducing, the overall performance of organization, human resource information system/IT supports the fundamental transformations regarding the HR function. If we think about the impact of HRIS on the human resource regular operations, many researchers have experimented HRIS from its functions (i.e. the online recruiting system, online selection system, online performance evaluation and e-compensation system) and indicated that HRIT can have both positive and negative impacts on human resource function [20]. According to the exploration on these functions, the perception of HRIS power on the transformation of human resource function can propagate from the information flows, social interaction systems, perceived individuals control and system adaptation [21] [22].

The program of HRIS can improve the information flows dramatically, as it possesses users much more effectively to gather, publish and access the informa- 
tion [20]. For instance, if we talk about the recruitment system, inquiry HRIS can make the candidates flexible to be acquired information about jobs and to access to the HR professionals without the direct face-to-face interview. In addition, HRIS is able to provide quicker response to employees, and develop the assisting capacity of an organization.

The sharing information among the different departments can assist the human resource experts holding the entire and perfect information on developing methods. There are still some limitations on this aspect, although HRIS is developing an organization's capability on data collection and management system. For example, the e-performance management system might not have included the all the behavioural measurements of the employees as the HRIS may measure the quantity but not the quality [23]. HRIS allows the HR experts to manipulate a large amount of data set ensuring very prominent accuracy. It is concerned to be the ideal way to increase the utility of HR function is the automation of HRIS. In contrast, in some special cases, the traditional methods may work better and more useful as HRIS may failed to provide satisfactory outcome [24]. Thinking of its capacity of causing the overall contribution to organization, HRIS helps the essential transformations with regards to the HR performance.

\section{Hypothesis}

The powerful Information System/IT programs are connected together with the developing involvement in HR experts on typically the role of change agent and the strategic function of business [24]. The greater frequent usage of IS-supported human resources programs, the more efficient on tactical issue associated with the HR function [25]. These people argue that the HRIS permits HR experts in order to conduct wide range of information along with high speed and dependability, which causes much better effective information management.

It offers HR experts to focus more on the particular time needed to direct their attempt towards more business critical and strategic level tasks, such as development of leadership and talent management. HRIS provides a great scope for HR to play a more strategic role, through their capability to develop metrics that can be used to corroboration strategic decision-making [26]. In order to our proposed hypothesis as follows:

H1: Information system/IT have significant effect on human resource performance.

HRIS is conducted towards the HR department itself [27]. However, the exercise of HRIS can provide a lot of advantages not only to the HR function, but also line managers, and the wider organization [28]. Typically the usages of HRIS have been advocated as a possibility for HR specialists to become strategic companions with top management. To make more proficient, HRIS permit HR function that provides better information on decision making [29]. The usages of the HRIS would decrease the cost of HR by automatically manipulating information and assist to decrease the demand of large numbers of HR employees; 
by assisting employees controlling their own personal information, and permitting managers to access corresponded information, conduct analysis, make decisions, and communicate with others without taking advice from HR specialists [30] [31]. Thus, we propose the hypothesis as follows:

$\mathrm{H} 2$ : A human resource information system supports/has significant impact on/the transformation of human resource performance.

The particular electronic inter-connectivity between two or more companies has become the competitive necessity to decrease the cost and improve solutions [32]. With the utilization of IT, companies have been able to incorporate their internal activities as well as external functions, therefore improving the ability to deal with the particular superior requirements of customers and the quality standards of goods [33] [34]. Due to the fact of using networks, shared databases, and other related info systems have been regarded as important for eliminating replicate activities, stopping errors, decreasing cycle time of product development, and increasing inter-organizational communications, companies have not reorganized the advantages of information system. Thus, we propose the hypothesis as follows.

H3: There is perception and ability of using information system/IT and human resource information system in employees.

\section{Research Method}

\section{Interview:}

In conducting this study, the researcher made on attempt to use both primary and secondary methods of data source in order to come up with more comprehensive information. The crucial data for this study were collected with the application of mainly the primary data sources including structured and unstructured interview online.

The question which the researchers were addressed to those respondents was focused on the Impact on information system on transformation of human resource performance. The study was used both qualitative and quantitative research approach. The researcher used descriptive type of qualitative methods; since the researcher were describing the opinions and feelings of respondents. In addition, the cross-sectional methods have been used because of researcher contact the respondents once by interviewing using online. The technique the researcher used in this study was non probability sampling techniques to gate quality of information from the employees. Among the employees of the organization, the researchers were selected 20 employees purposively based on management level, like top level management, middle level management and low level management. Among those, 4 (20\%) of respondents were top level managers, 7 (35\%) were middle level, while 9 (45\%) were low level.

This research work is primarily interested in ascertaining the impact of information system/IT on transformation of human resource performance, the case of Oromia radio and television organization in Ethiopia. 


\section{Choices of Respondents:}

The choices of respondents for this research were chosen from the particular individuals who have been involved in the Human Recourse Information System of Oramia Radio and Television Organization. Being part of HRIS, we believed that participants would be able to provide details of the information which would be relevant for this study. These types of interviews were based upon the specific problems that are mentioned. In this research, structured interviews were used by conducting direct face-to-face, telephone, and e-mail interviews, a much better understanding of problems plus the current situation associated with the case are acquired.

Typically, the interview time was roughly an hour or so, the time various from 40 minutes to be able to 90 minutes. In addition, sound recording was carried out by a recorder gadget to be able to support arranging the particular information further when we wrote in the study paper and, also, to avoid misunderstanding in the future. The drawbacks with selecting qualitative research are that typically the collected data could possibly be prejudiced.

\section{Results}

To improve the efficiency and capability of the organization, the transformation process of HR has shown the direction to provide higher quality services. The future trend of HR function is to widely utilize Information system or information technology. The researcher proposed three hypotheses to be tested in this study to arrive at the meaningful conclusion. The proposed hypothesis was expected to provide a clear picture of impact of information system on transformation of human resource performance in Oromia radio and television organization. Figure 3 illustrates the impact of IS on transformation of HR performance in ORTO.

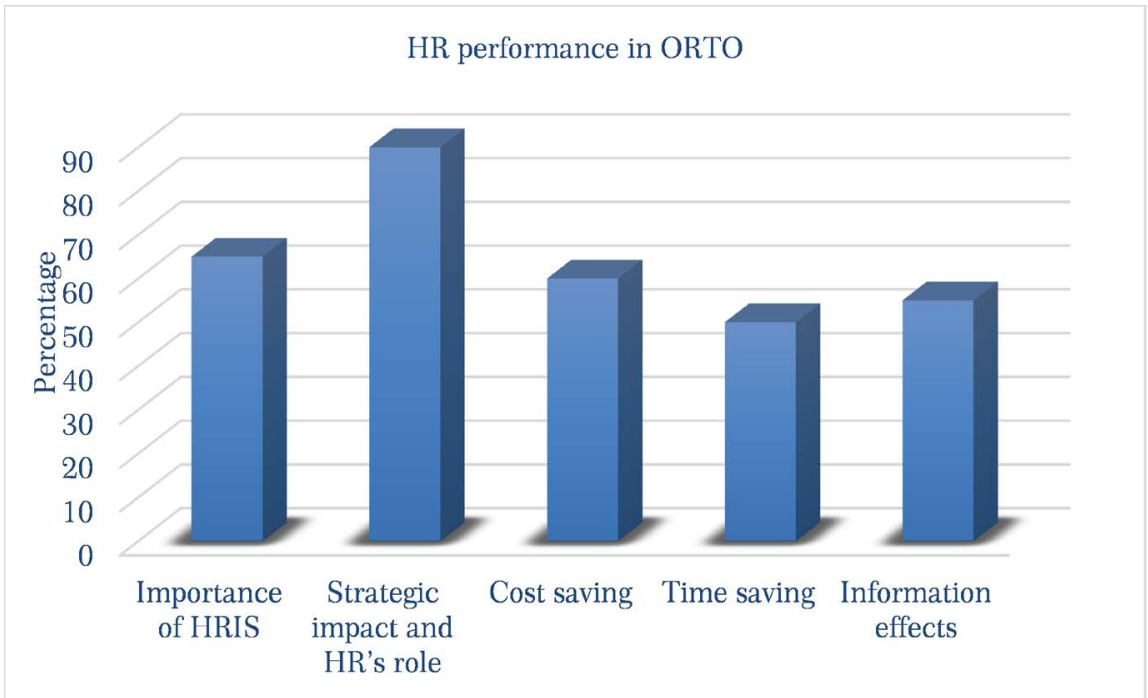

Figure 3. The impact of IS on transformation of HR performance in ORTO. 
Over $65 \%$ of the respondents were of the opinions that, information system are important on human resource performance in Oromia radio and television organization.

Majority of respondents (85\%) of respondents were strongly believed that human resource information system is important.

Large number of respondents (55\%) was leveled the utilization of human resource information system as very high and high.

Over (90\%) respondents believed that the implementation of human resource information system brought change in improving the working environment of organization.

Around half of the respondents (50\%) responded as neutral that importance of human resource information system on management decision making in Oromia radio and television organization.

Majority of respondents (60\%) opinion revealed that human resource information system plays significant role in terms of cost saving.

Around half $(50 \%)$ respondents agreed that human resource information system effectively decreases the time spent on daily activities of employees in Oromia radio and television organization.

More than half (55\%) of respondents' opinion showed that human resource information system plays role in eliminating paper forms that are much slower and with lower probability of errors.

> Among 45\% of respondent's response that human resource information system has effectively improved their ability to share information between workers at medium level.

\section{Hypothesis Testing:}

Hypothesis 1: Information system/IT have significant effect on human resource performance.

Figure 4 shows that $65 \%$ of the respondent's response that the role of information system on transformation of human resource performance is extremely very high, $25 \%$ response that at very high level, while $10 \%$ answered as high. However, the survey showed that majority of the respondents believed that the role of Information system on human resource performance is extremely very high. In according to the unstructured questions results, majority of respondents respond that, human resource information system benefited their organization in different ways like: in improving accuracy, the provision of timely and quick access to information and in saving costs and also benefited them in several administrative and strategic advantages. In the following way the hypothesis is accepted.

Hypothesis 2: A human resource information system supports/has significant impact on the transformation of human resource performance.

From Figure 5 and Figure 6, the researcher finds that, 100\% of respondents believe human resource information system have impact or plays crucial role in transformation of human resource performance. As of the data obtained from 


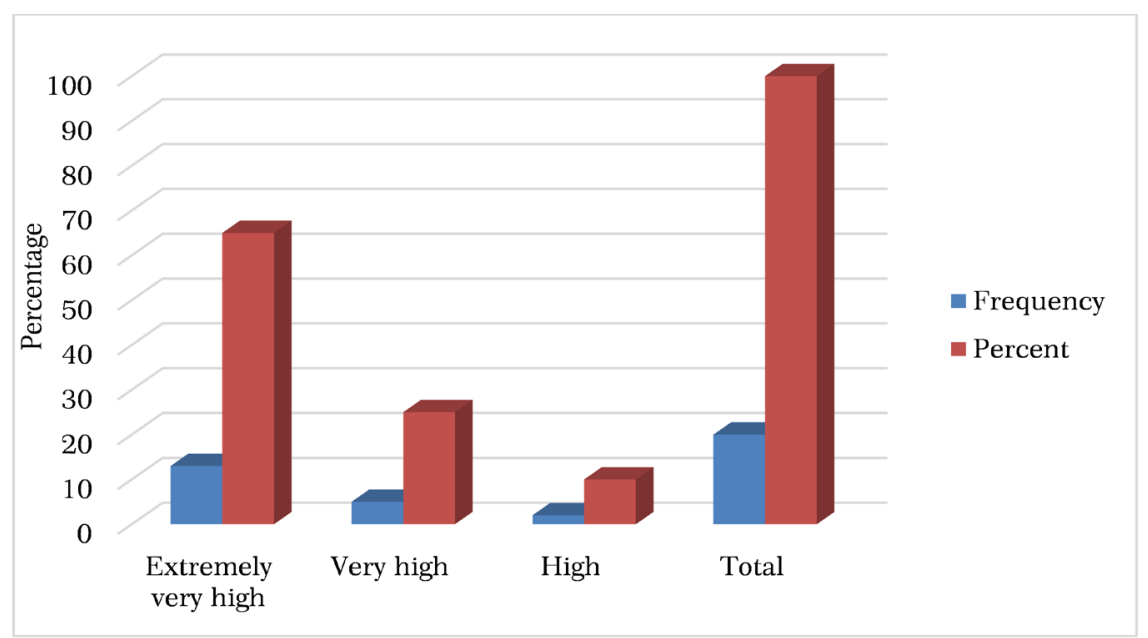

Figure 4. Role of information system on human resource performance.

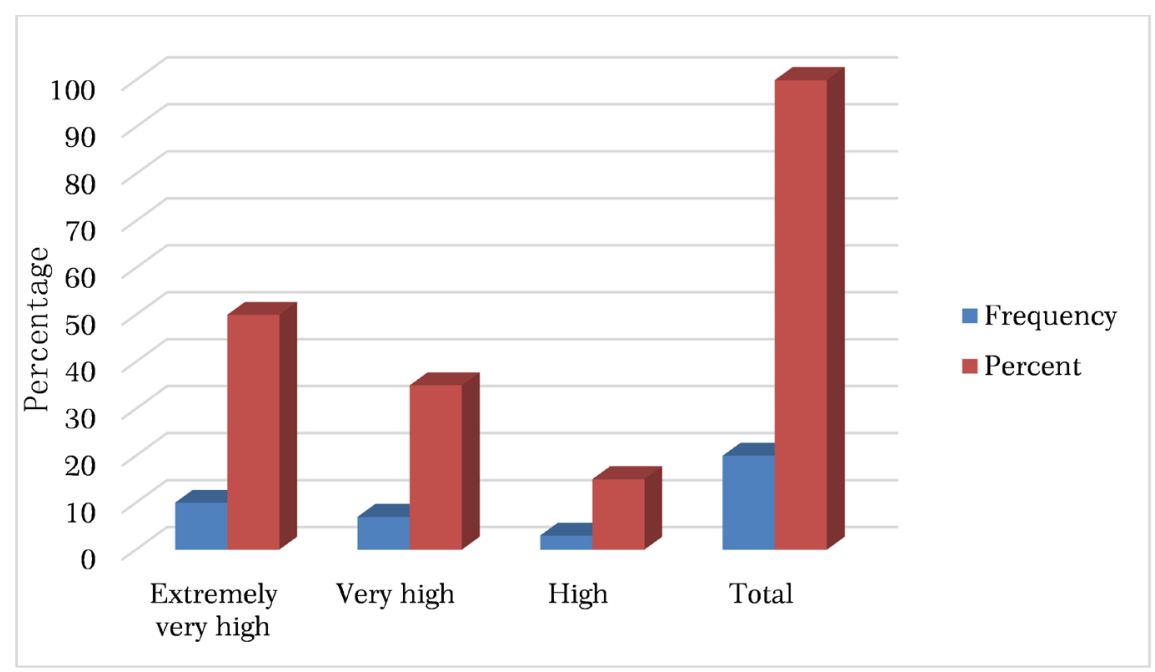

Figure 5. Importance of HRIS on management decision making.

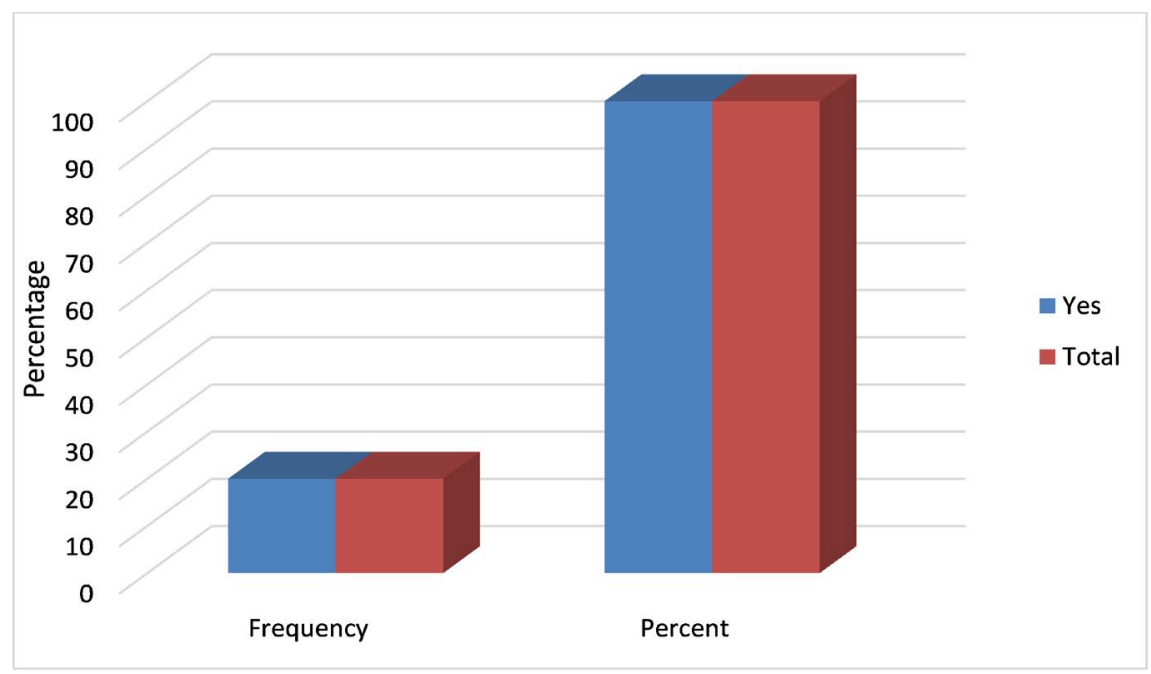

Figure 6. Positive impact of HRIS on transformation of HR performance. 
the respondents using unstructured interview, the majority of interviewed answered that, in order to transform human resource performance by enabling easiest access and convenient work environment to make the day to day transactions/activities across different departments and employees by making efficient and effective work process. From the above data we can conclude that, Human resource information system plays a significant role in transforming the human resource performance. Thus, the hypothesis is accepted.

Hypothesis 3: There is ability/knowledge of using information system/IT and human resource information system in employees.

Figure 7 demonstrates that $60 \%$ of respondents answered that their ability/knowledge of using information system/IT at (very strong and strong) level. $30 \%$ of respondents a sure that their knowledge of using Information system/IT is at medium level, while $10 \%$ of respondents respond at poor level. From the result it was showed that majority of the respondent's ability of using Information system/IT is strong. Thus, the hypothesis is accepted.

\section{Limitations and Future Direction}

This research work was based on the impact of Information system/IT on transformation of human resource performance in Oromia radio and television organization which was based in Ethiopia, Oromia region as case study. In conducting this research, the researcher faced lack of budget (finance), due to this reason, the researcher forced to conduct and gather data online via. If there have been allocated enough budget, the researcher would travel and present physically to the study area and could collect enough data from more employees.

Consequently, a cross-disciplinary research group should be employed in order researchers from both technologies side and business side can try to understand from one another to alleviate the knowledge gap, also to find out the new chance of technology software to improve the business.

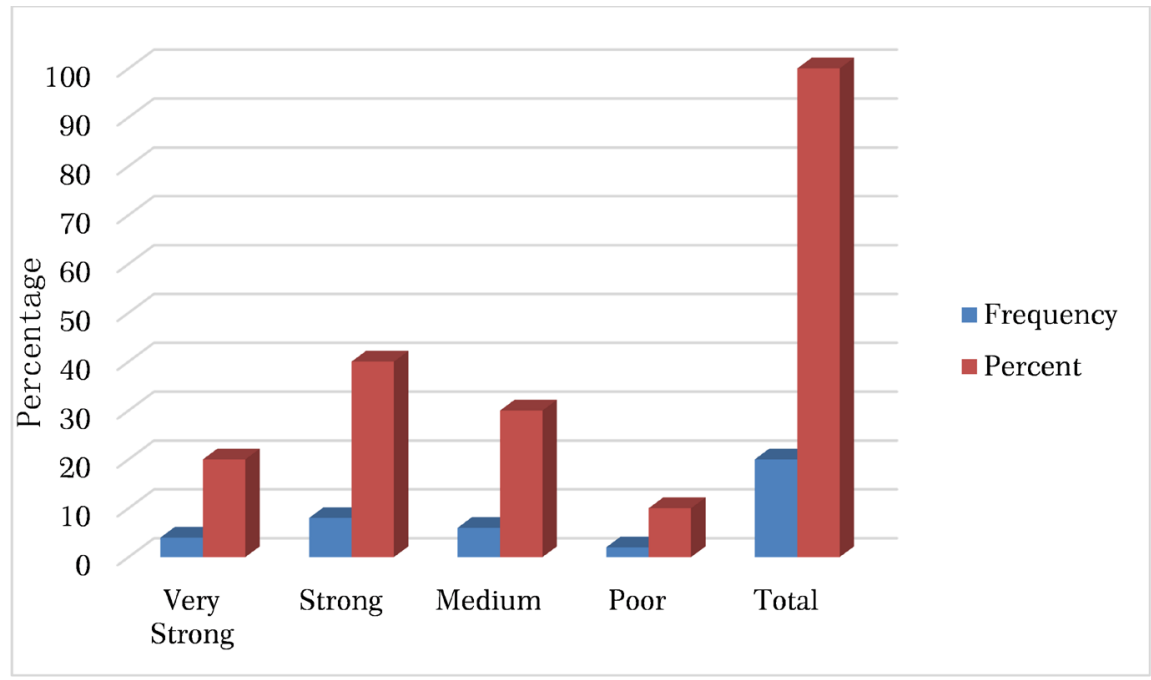

Figure 7. Response on ability/knowledge of using Information system/IT. 
Simultaneously, investigation should be provided for the organization to observe how employees in the world industry expand their expertise border to fully equip the particular HRIS platform, and also to smooth the transformation process what can be done, in order that it can be revolved around technology-driven into business-objective-driven. Finally, HRIT becomes a progressively significant factor of modification of human resource efficiency, researchers should concentrate their particular perception of the advantages and threats that HRIT brings.

\section{Conclusions}

Based on the study of HR managers of Oramia radio and television organization, the result concerning of HRIS is much impressive. Human resource information system plays a vital role in strategic HR tasks in this organization.

That changes the management means of traditional HRM, permits these kinds of administrational mobility can bring out at any stage without further barrier-leading and line management, employee's self-management and foreign authority. Apart from working with the info transaction, the strategy of human resources works such as workplace studying, job management, business procedure reengineering, and so on is heading in order to be better flourished and adopted along with the HRIT application, which usually supports human resource function as an even more useful position.

The majority of respondents assure that as human resource information system plays a great role in time and cost saving and also improving the working environment of the organizations. So, human resource information system plays a key role in improving and transforming human resource performance. Generally, the digitization of HRIS has resulted in a good integrated database of HR files, position documents, employee records, catalog files, work analysis plus design files, affirmative action files, health and safety documents, and many others related to HR are built in a coordinated way using database management techniques software, to ensure that application can generate reports through any or all of the documents. Therefore, the human resource administration can generate reports listing possibly internal individuals for open positions simply by running an application system that queries position documents, skills catalog files, plus job requirements files. Sustaining human resource data in a variety of personal databases is less successful than storing it in one database and having all applications access the data as needed.

\section{Acknowledgements}

The authors would like to thank Oromia Radio and Television Organization for sharing their info and assisting to conduct the survey.

\section{References}

[1] Wyatt, W. (2002) Human Capital as a Lead Indicator of Shareholder Value: 
2001/2002 Survey Report. Watson Wyatt Worldwide, Washington DC.

[2] Jacoby, S.M., Nason, E.M. and Saguchi, K. (2005) The Role of the Senior HR Executive in Japan and the United States: Employment Relations, Corporate Governance and Value. Industrial Relation: A Journal of Economy and Society, 44, 207-241.

[3] Bjorkman, I. and Soderberg, A.M. (2006) The HR Function in Large-Scale Mergers and Acquisitions: The Case Study of Nordea. Personnel Review, 35, 654-670. https://doi.org/10.1108/00483480610702719

[4] Appelbaum, S.H. and Wohl, L. (2000) Transformation or Change: Some Prescriptions for Health Care Organizations. Managing Service Quality, 10, 279-298. https://doi.org/10.1108/09604520010345768

[5] Svoboda, M. and Schroder, S. (2001) Transforming Human Resources in the New Economy: Developing the Next Generation of Global HR Managers at Deutsche Bank. Human Resource Management, 40. https://doi.org/10.1002/hrm.1016

[6] Knapp, D. (2004) If You're in HR, You're Likely in HR Transformation. Employee Benefit Plan Review, 58, 9-13.

[7] Stockport, G.J. (2000) Developing Skills in Strategic Transformation. European Journal of Innovation Management, 3, 45-52. https://doi.org/10.1108/14601060010305256

[8] Beadles II, N.A., Lowery, C,M. and Kim, J. (2005) The Impact of Human Resource Information Systems: An Exploratory Study in the Public Sector. Communications of the IIMA, 5.

[9] Sagie, A. and Weisberg, J. (2001) The Transformation in Human Resource Management in Israel. International Journal of Manpower, 22, 226-234. https://doi.org/10.1108/01437720110398275

[10] Selmer, J. (2001) Expatriate Selection: Back to Basics? International Journal of Human Resource Management, 12, 1219-1233. https://doi.org/10.1080/09585190110083767

[11] Yeung, A., Brockbank, W. and Ulrich, D. (1994) Lower Cost, Higher Value: Human Resource Function in Transformation. Human Resource Planning, 17, 1-16.

[12] Mohrman, S.A. and Lawler, E.E. (1997) Transforming the Human Resource Function. Human Resource Management, 36, 157-162. https://doi.org/10.1002/(SICI)1099-050X(199721)36:1<157::AID-HRM25>3.0.CO;2 $-7$

[13] Rowley, C. and Bae, J. (2002) Globalization and Transformation of Human Resource Management in South Korea. International Journal of Human Resource Management, 13, 522-549. https://doi.org/10.1080/09585190110111512

[14] DeSanctis, G. (1986) Human Resource Information Systems: A Current Assessment. MIS Quarterly, 10, 15-27. https://doi.org/10.2307/248875

[15] Mclver, D., Lengnick-Hall, C.A., Lengnick-Hall, M.L. and Ramachandran, I. (2012) Integrating Knowledge and Knowing: A Framework for Understanding Knowledge-in-Practice. Human Resource Management Review, 22, 86-99. https://doi.org/10.1016/j.hrmr.2011.11.003

[16] Kovach, K.A. and Cathcart Jr., C.E. (1999) Human Resource Information Systems (HRIS): Providing Business with Rapid Data Access, Information Exchange and Strategic Advantage. Public Personnel Management, 28, 275-282. https://doi.org/10.1177/009102609902800208

[17] Baines, T.S., Asch, R., Hadfield, L., Mason, J.P., Fletcher, S. and Kay, J.M. (2005) 
Towards a Theoretical Framework for Human Performance Modelling within Manufacturing Systems Design. Simulation Modelling Practice and Theory, 13, 486-504. https://doi.org/10.1016/j.simpat.2005.01.003

[18] Krishna, Y.S. and Bhaskar, S.V. (2011) Assessment of Support and Benefits of HRIS in Medium-Scale Textile Industries. International Journal of Research in Economics \& Social Sciences, 1, 2249-7382.

[19] Florkowski, G.W. and Olivas-Lujan, M.R. (2006) The Diffusion of Human-Resource Information-Technology Innovations in US and Non-US Firms. Personnel Review, 35, 684-710.

[20] Stone, D.L. and Lukaszewski, K.M. (2009). An Expanded Model of the Factors Affecting the Acceptance and Effectiveness of Electronic Human Resource Management Systems. Human Resource Management Review, 19, 134-143. https://doi.org/10.1016/j.hrmr.2008.11.003

[21] Ashbaugh, S. and Miranda, R. (2002) Technology for Human Resource Management: Seven Questions and Answers. Public Personnel Management, 31, 7-20.

[22] Stone, D.L., Lukaszewski, K.M., Stoneromero, E.F. and Johnson, T.L. (2013) Factors Affecting the Effectiveness and Acceptance of Electronic Selection Systems. Human Resource Management Review, 23, 50-70.

https://doi.org/10.1016/j.hrmr.2012.06.006

[23] Stone, D.L., Lukaszewski, K.M., Stoneromero, E.F. and Lukaszewski, K. (2006) Factors Affecting the Acceptance and Effectiveness of Electronic Human Resource Systems. Human Resource Management Review, 16, 229-244.

https://doi.org/10.1016/j.hrmr.2006.03.010

[24] Haines III, V.Y. and Lafleur, G. (2008) Information Technology Usage and Human Resource Roles and Effectiveness. Human Resource Management, 47, 525-540.

[25] Ashbaugh, S. and Miranda, R. (2002) Technology for Human Resources Management: Seven Questions and Answers. Public Personnel Management, 31, 7-20. https://doi.org/10.1177/009102600203100102

[26] Lawler, E.J. and Mohrman, S.A. (2003) HR as a Strategic Partner: What Does It Take to Make It Happen? Human Resource Planning, 26, 15-29.

[27] Ruël, H., Bondarouk, T. and Loosie, J.K. (2004) E-HRM: Innovation or Irritation. An Explorative Empirical Study in Five Large Companies on Web-Based HRM. Management Revue, 15, 364-380.

[28] Bown-Wilson, D. and Parry, E.S. (2009) Career Plateauing in Older Workers: Contextual and Psychological Drivers. In: Baugh, G.A. and Sullivan, S.E., Eds., Maintaining Focus, Energy, and Options through the Lifespan, Information Age, Charlotte, NC, 75-105.

[29] Beadles II, N.A., Lowery, C.M. and Johns, K. (2005) The Impact of Human Resource Information Systems: An Exploratory Study in the Public Sector. Communications of IIMA, 5, 39-46.

[30] Awazu, Y. and Desouza, K.C. (2003). Knowledge Management. HR Magazine, 48, 107.

[31] Ball, K.S. (2001) The Use of Human Resource Information Systems: A Survey. Personnel Review, 30, 667-693. https://doi.org/10.1108/EUM0000000005979

[32] Bhatt, G.D. (2000) An Empirical Examination of The Effects of Information Systems Integration on Business Process Improvement. International Journal of Operation \& Production Management, 20, 1331-1359. https://doi.org/10.1108/01443570010348280 
[33] Bardi, E.J., Raghunathan, T.S and Bagchi, P.K. (1994) Logistics Information Systems: The Strategic Role of Top Management. Journal of Business Logistics, 15, 71-85.

[34] Narasimhan, R. and Carter, J.R. (1998) Linking Business Unit and Material Sourcing Strategies. Journal of Business Logistics, 19, 155-171. 